\title{
Serum Vitamin D Level and it's Clinical Correlation with Rheumatological Diseases
}

\author{
Razzak MA', Rahman $\mathrm{MA}^{2}$, Begum $\mathrm{MUH}^{3}$, Islam MI ${ }^{4}$ \\ DOI: https://doi.org/10.3329/jafmc.v14i2.45884
}

\begin{abstract}
Introduction: Vitamin D deficiency or insufficiency is a worldwide problem including Bangladesh. It is common in Rheumatological diseases.
\end{abstract}

Objectives: To find outthe clinical correlation of serum Vitamin $\mathrm{D}$ level with Rheumatological diseases.

Materials and Methods: This was a hospital based case control study. It was conducted in Rheumatology department of Combined Military Hospital Dhaka. Total 100 patients having Rheumatological diseases and 100 age and sex matched healthy control were included in the study. Data were collected from face to face interview, clinical examination and relevant investigation reports and processed with SPSS version 20 and obtained in tables and charts.

Results: Among 100 study patients'Osteoarthritis (OA) were 24(24.0\%), Rheumatoid arthritis (RA) 20(20.0\%), SLE 16(16.0\%), Osteoporosis 16(16.0\%), Ankylosing spondylitis (AS) 10(10.0\%), Chikungunya arthritis (CS) 4(4.0\%)and other arthritis 10(10.0\%). Among patients group $84(84.0 \%)$ had vitamin D deficiency/ insufficiency, of whom OA were 20(23.80\%), RA 16(19.04\%), SLE 16(19.04\%), osteoporosis 14 (16.66\%),AS 8(9.52\%), CS 2(2.38\%) and other arthritis 8(9.52\%).Abnormal vitamin D level were in SLE 16(100.0\%), osteoporosis 14(87.50\%), OA20(83.33\%), RA(80.0\%), AS $8(80.0 \%)$, CS $2(50.0 \%)$, and other arthritis $8(80.0 \%)$.In study patients, 60 had adequate sun exposure of whom $48(72.07 \%)$ had low serum vitamin $D$ level and 40 had inadequate sun exposure of whom $36(90.0 \%)$ had low vitamin D level that reflects sunlight exposure affects vitamin $\mathrm{D}$ status.Abnormal serum vitamin $\mathrm{D}$ level was more common in Rheumatological diseased patients than healthy group $(p<0.01)$.

Conclusion: Abnormal vitamin $D$ level were more in Rheumatological diseases than healthy control group that was statistically significant; it was also affected by lifestyle of patients.

Key-words: Vitamin D, Rheumatological disease. Systemic Lupus Erythematosus.

\section{Introduction}

Vitamin $D$ is a steroid hormone that plays essential roles in calcium and phosphate metabolism, bone formation and mineralization. It has been appreciated for its role in calcium homeostasis and bone ${ }^{1}$ health since its identification in 1921. Vitamin $D$ also has immune-regulatory role and affects both the innate and adaptive immune system cells contributing to the immune-tolerance of self-structures ${ }^{2}$. Vitamin $D$ is synthesized in vivo when solar ultraviolet $B$ (UVB) radiation interacts with the precursor molecule, 7-dehydrocholesterol in the skin ${ }^{1}$. The other important source of vitamin $D$ is dietary intake and supplementation. After synthesis of vitamin D in the skin in response to ultraviolet radiation or absorption from diet, it is transported to the liver, where it undergoes 25 -hydroxylation and forms 25-hydroxyvitamin D. This metabolite is the major circulating form of vitamin $D$. The final step in hormone activation, 1a-hydroxylation, occurs in the kidney and forms ${ }^{1}, 25$-dihydroxyvitamin $D$, active form of vitamin $D^{3}$. A $25(\mathrm{OH}) \mathrm{D}$ concentration $<50 \mathrm{nmol} / \mathrm{L}$ is considered vitamin $D$ deficiency, whereas concentration $51-74 \mathrm{nmol} / \mathrm{L}$ is considered insufficiency of vitamin $D$ and concentrations $\geq 75$ $\mathrm{nmol} / \mathrm{L}$ are considered to be sufficient ${ }^{4}$.

Endogenous production of Vitamin D is estimated to account for $90 \%$ of total vitamin $\mathrm{D}$ in healthy individual, and any activity that reduces sunlight exposure will tend to reduce vitamin $D$ level $\left.\right|^{5}$. Aging is also associated with decreased concentrations of 7-dehydrocholesterol, the precursor of Vitamin D3 in the skin and they have a $75 \%$ reduced capacity to make vitamin D3 in the skin $^{3}$. Other causes of vitamin D deficiency are associated with nutritional deficiency, obesity, lipid disorders and medications including antiseizure drugs, glucocorticoids and fat malabsorption ${ }^{6}$.

Low vitamin $D$ status is reported in many inflammatory rheumatic conditions. Vitamin $\mathrm{D}$ acts on a number of cells involved in both innate and acquired immunity biasing the adaptive immune system away from the Th17 and Th1, towards

\footnotetext{
1. Brig Gen Md Abdur Razzak, MBBS, MCPS (Medicine), FCPS (Medicine), APLAR Clinical Fellow Rheumatology, Professor and Head, Dept. of Medicine, Armed Forces Medical College, Dhaka Cantonment (E-mail:razzakprm@yahoo.com) 2. Lt Col Md Anisur Rahman, MBBS, FCPS (Medicine), OJT- Interventional Gastroenterology (India), Classified Specialist in Medicine and Gastroenterologist, Dept. of Gastroenterology, CMH, Dhaka Cantonment. 3. Dr Most. Umme Habiba Begum, MBBS, FCPS (Paediatrics), Associate Professor, Dept. of Paediatrics, Rangpur Community Medical College. 4. Maj Md Ifthakharul Islam, MBBS, Graded Specialist in Medicine, Outpatient Clinic, Bhatiary, Chattogram.
} 
$\mathrm{Th}^{2}$ and Tregs (Regulatory T cells). Deficiency accordingly could encourage autoimmunity. Vitamin $D$ deficiency may be an important factor in autoimmune rheumatic disease such as Rheumatoid arthritis (RA), Systemic lupus erythematosus (SLE), systemic sclerosis etc. It has also possible role in initial disease development and worsening the diseases once present ${ }^{7}$. An inadequate level of vitamin $D$ has been linked to a number of other diseases including metabolic disorders, other autoimmune conditions, as well as osteoporosis and osteomalacia ${ }^{8}$. Vitamin $D$ has immunoregulatory activity which is mediated through VDRs present on antigen presenting cells, activated-T lymphocytes and activated-B lymphocytes. Various studies done so far suggest that vitamin $D$ deficiency increases the risk of developing autoimmune diseases including RA and SLE. In Bangladesh, well documented data regarding correlation of vitamin $D$ status in relation to Rheumatologucal diseases is presently scarce. In current study we have tried to correlate vitamin $D$ level in patients of common Rheumatological diseases as well as in healthy control group.

\section{Materials and Methods}

The aim of this study was to correlate vitamin $D$ status in patients with musculoskeletal diseases like osteoarthritis (OA), SLE, ankylosing spondylitis (AS), RA, osteoporosis and other Rheumatological diseases and comparing vitamin D status with healthy individuals. This study was a hospital based case control study, carried out in Rheumatology department of Combined Military Hospital (CMH) Dhaka cantonment from July 2017 to June 2019. Total 100 patients having any Rheumatological disease or patients presented with clinical, laboratory and imaging evidences suggesting Rheumatological disease were included in the study group. Hundred age and sex matched healthy individuals were also investigated for vitamin D level as control group. Critically ill patients, extremes of age $(<16$ and $>80$ years $)$, pregnancy, currently vitamin D supplementation and know chronic liver disease and chronic kidney disease patients were excluded from the study. Verbal consents were taken and all patients were interviewed face to face as per questionnaire and clinical examination and investigations were done. Data was collected and analyzed by using SPSS 20 and formulated in tables and charts.

\section{Results}

Patients demographic profile of study group shown in Table-I.Among 100 patients, 60(60.0\%) used to expose under sun regularly and 40 (40.0\%) irregularly/ inadequately; 48(48.0\%) used Bhurkha/veil, 34(34.0\%) smoker, 7(7.0\%) took tobacco in other forms and 3(3.0\%) used to take alcohol. Presenting complains of study patients; arthralgia 96(96\%), backache 74(74\%), joint swelling 66(66\%), morning stiffness $64(64 \%)$, myalgia $56(56 \%)$, bone pain $54(54 \%)$, skin rash/lesion $30(30 \%)$, restricted joint movement $24(24 \%)$, weight loss $16(16 \%)$, joint deformity $12(12 \%)$, extra-articular features 10(10\%).Among 100 patients, Osteoarthritis were $24(24.0 \%)$, Rheumatoid arthritis 20(20.0\%), SLE 16(16.0\%), Osteoporosis 16(16.0\%), Ankylosing spondylitis 10(10.0\%), Chikungunya arthritis 04(4.0\%) and 10(10.0\%)other arthritis (Table-II). Figure-1 shows comparison of vitamin $D$ status in between study group and healthy group; in study group deficient were in $12(12.0 \%)$, insufficient $72(72.0 \%)$ and sufficient $16(16.0 \%)$, whereas in healthy control group deficient were in $4(4.0 \%)$, insufficient $46(46.0 \%)$, sufficient 50(50.0\%). Total abnormal values were found in $84(84 \%)$ in study group and $50(50 \%)$ in control group.Among 100 patients having Rheumatolgical diseases $84(84 \%)$ had vitamin D deficiency/insufficiency. Hundred percent of SLE patients, $87.50 \%$ of osteoporosis, $83.33 \%$ of osteoarthritis, $80 \%$ of RA, AS and other arthritis, $50 \%$ of Chikungunya had low levels of vitamin D (TableIII). Among 84 patients who had abnormal vitamin D level (deficient and insufficient) female were 60(71.43\%) and 24(28.57\%) male (Figure-2). Among 100 study patients, 60 had adequate sun exposure of whom $48(80.0 \%$ ) had low serum vitamin $D$ level and 40 had infrequent/ inadequate sun exposure of whom $36(90.0 \%)$ had low vitamin D level that reflected sunlight exposure affects vitamin $D$ status (Table-IV).Rheumatological diseases patients had abnormal serum vitamin $D$ level in comparison to healthy control group and it was statistically significant $(p<0.01)$.

Table-I: Demographic profile of study population $(n=100)$

\begin{tabular}{|c|c|c|c|}
\hline \multicolumn{2}{|c|}{ Variables } & Frequency & Percentage \\
\hline \multirow{6}{*}{ Age in years } & $<20$ & 05 & 05 \\
\hline & $20-30$ & 15 & 15 \\
\hline & $31-40$ & 18 & 18 \\
\hline & $41-50$ & 16 & 16 \\
\hline & $51-60$ & 20 & 20 \\
\hline & $>60$ & 26 & 26 \\
\hline \multirow{2}{*}{ Gender } & Female & 72 & 72 \\
\hline & Male & 28 & 28 \\
\hline \multirow{2}{*}{ Religion } & Muslim & 92 & 92 \\
\hline & Hindu & 8 & 8 \\
\hline \multirow[b]{2}{*}{ Residence } & Urban & 56 & 56 \\
\hline & Rural & 44 & 44 \\
\hline \multirow{4}{*}{ Occupation } & Housewife & 32 & 32 \\
\hline & Retired & 28 & 28 \\
\hline & Service & 22 & 22 \\
\hline & Others & 12 & 12 \\
\hline \multirow{2}{*}{ Sun exposure } & Adequate & 60 & 60 \\
\hline & Inadequate & 40 & 40 \\
\hline \multicolumn{2}{|c|}{ Using Bhurkha/veil } & 48 & 48 \\
\hline \multirow{2}{*}{ Using tobacco } & Smoking & 34 & 34 \\
\hline & Smokeless tobacco & 07 & 07 \\
\hline Alcoholism & & 03 & 03 \\
\hline Total & & 100 & 100 \\
\hline
\end{tabular}


Table-II: Distribution of Cases by presenting complaints and type of diseases $(n=100)$

\begin{tabular}{|c|c|c|c|}
\hline & Characteristics & Frequency & Percentage \\
\hline \multirow{12}{*}{$\begin{array}{l}\text { Presenting } \\
\text { complaints }\end{array}$} & Arthralgia & 96 & 96 \\
\hline & Backache & 74 & 74 \\
\hline & Joint swelling & 66 & 66 \\
\hline & Morning stiffness & 64 & 64 \\
\hline & Myalgia & 56 & 56 \\
\hline & Bone Pain & 54 & 54 \\
\hline & Skin Rash/lesion & 30 & 30 \\
\hline & Restricted joint movement & 24 & 24 \\
\hline & Weight loss & 16 & 16 \\
\hline & Joint deformity & 12 & 12 \\
\hline & Other Extra-articular feature & 10 & 10 \\
\hline & Total & 100 & 100 \\
\hline \multirow{8}{*}{$\begin{array}{l}\text { Type of } \\
\text { Diseases }\end{array}$} & Osteoarthritis & 24 & 24.0 \\
\hline & Rheumatoid arthritis & 20 & 20.0 \\
\hline & SLE & 16 & 16.0 \\
\hline & Osteoporosis & 16 & 16.0 \\
\hline & Ankylosing arthritis & 10 & 10.0 \\
\hline & Chikungunya arthritis & 04 & 4.0 \\
\hline & Other arthritis & 10 & 10.0 \\
\hline & Total & 100 & 100 \\
\hline
\end{tabular}

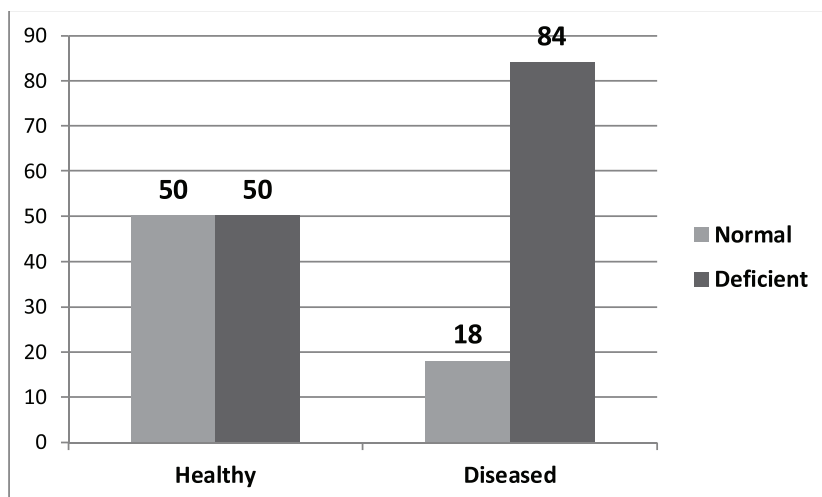

Figure-1: Comparison of vitamin $D$ status in patients of study group and healthy control group ( $\mathrm{n}=100$ each)

Table-III: Disease wise vitamin $D$ deficiency and insufficiency in study patients $(n=84)$

\begin{tabular}{|l|c|c|c|}
\hline \multicolumn{1}{|c|}{ Diseases } & $\begin{array}{c}\text { No of } \\
\text { cases }\end{array}$ & $\begin{array}{c}\text { Vitamin D deficiency/ } \\
\text { insufficiency }\end{array}$ & $\begin{array}{c}\text { Percentage } \\
(\%)\end{array}$ \\
\hline SLE & 16 & 16 & 100 \\
\hline Osteoporosis & 16 & 14 & 87.50 \\
\hline OA & 24 & 20 & 83.33 \\
\hline RA & 20 & 16 & 80.0 \\
\hline AS & 10 & 8 & 80.0 \\
\hline Chikungunya arthritis & 4 & 2 & 50.0 \\
\hline Other arthritis & 10 & 8 & 80.0 \\
\hline Total & 100 & 84 & 84.0 \\
\hline
\end{tabular}

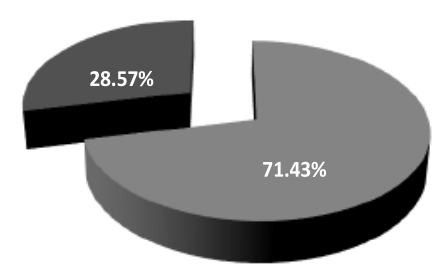

Female Male

Figure-2: Sex distribution of abnormal serum Vitamin $D$ in study group $(\mathrm{n}=84)$
Table-IV: Correlation of sun exposure to low vitamin D in study patients $(n=100)$

\begin{tabular}{|l|c|c|c|}
\hline \multicolumn{1}{|c|}{ Sun exposure } & \multirow{2}{*}{$\begin{array}{c}\text { Total } \\
\text { subject }\end{array}$} & \multicolumn{2}{c|}{ Low vitamin D level } \\
\cline { 3 - 4 } & 60 & 48 & 80 \\
\hline Adequate & 40 & 36 & 90 \\
\hline Inadequate & & & \\
\hline & & & Frequency \\
\hline
\end{tabular}

Table-V: Summary of vitamin D status in study group and control group

\begin{tabular}{|c|c|c|c|}
\hline $\begin{array}{l}\text { Group of } \\
\text { Patient }\end{array}$ & $\begin{array}{c}\text { Abnormal Value } \\
\mathrm{n}(\%)\end{array}$ & $\begin{array}{c}\text { Normal Value } \\
\mathrm{n}(\%)\end{array}$ & Statistics \\
\hline Study Group & $84(84)$ & $16(16)$ & \multirow{3}{*}{$\begin{array}{l}\chi^{2}=8.283 \\
d f=1 \\
p<0.01\end{array}$} \\
\hline Control Group & $50(50)$ & $50(50)$ & \\
\hline Total & 134 (67) & $66(33)$ & \\
\hline
\end{tabular}

\section{Discussion}

Vitamin $\mathrm{D}$ deficiency is a global health problem caused mainly by insufficient exposure to sunlight. It is now recognized as a pandemic. No one is immune from vitamin $D$ deficiency, both children and adults living in the United States, Europe, Middle East, India, Australia, and Asia including Bangladesh. Studies suggest that upwards of $30-50 \%$ of children and adults are at risk of vitamin $D$ deficiency ${ }^{9}$. In other study ${ }^{10}$ from Dhaka, it was found that, in Bangladesh vitamin D insufficiency $(<40 \mathrm{nmol} / /)$ was common ( $80 \%$ ) regardless of age, lifestyle and clothing. In another study ${ }^{11}$ from Bangladesh, it was observed that women of Bangladesh were at risk of hypovitaminosis D. Seventy percent of women from low economic group and 12 percent of high economic group had serum vitamin $D$ concentration $<25$ $\mathrm{nmol} / \mathrm{L}$ and hypovitaminosis $\mathrm{D}(\leq 37.5 \mathrm{nmol} / \mathrm{L})$ was observed in $50 \%$ and $38 \%$ subjects in low and high economic group respectively. Rheumatological disorders are very common disorder worldwide. Some of the Rheumalogical disorders such as SLE, RA and other autoimmune disorders have causal relation with low Vitamin $D$ level and also might have role on disease activity. Vitamin $D$ level is particularly important as its deficiency is highly prevalent in this group ${ }^{12}$. Vitamin D seems to interact with the immune system through its action on the regulation and differentiation of cells such as lymphocytes, macrophages, natural killer cells, besides interacting in the production of cytokines ${ }^{13}$. Systemic lupus erythematosus, a systemic autoimmune disorder, can cause chronic inflammation and damage in several tissues and organs ${ }^{14}$. Evidences suggest that vitamin $D$ plays an important relationship in the pathogenesis and progression of SLE ${ }^{15}$. Vitamin D inadequacy is highly prevalent in SLE patients due to the avoidance of sunshine, photo protection, renal insufficiency and the use of medications such as glucocorticoids, anticonvulsants, antimalarials and the calcineurin inhibitors which alter the 
metabolism of vitamin $D$ or down regulate the functions of the vitamin $\mathrm{D}$ receptor ${ }^{16}$. Continuance insufficiency of vitamin $\mathrm{D}$ results in rickets and osteomalacia with skeletal deformities in children and bone pain and increased risk of fractures in adults $^{17}$. The risk of osteoporosis and bone fracture is also higher in patients with SLE ${ }^{18}$.

In current study, we found that vitamin D deficiency/insufficient were more common in study patients than healthy control group, deficiency $12(12.0 \%)$ versus $4(4.0 \%)$, and insufficient $72(72.0 \%)$ versus $46(46.0 \%)$ respectably. Rheumatolgical diseases in study patients were RA, osteoarthritis, osteoporosis, ankylosing spondylitis, SLE and other arthritis. Vitamin D level were lower in $100 \%$ SLE patients, $87.5 \%$ of osteoporosis, $83.33 \%$ of OA, $80 \%$ of RA, AS and other arthritis cases. The elderly population has been found to be a group of particular risk of vitamin $D$ deficiency. This is in part due to them producing less cholecalciferol with the same exposure to UVB light as younger adults but also to less time spent outside ${ }^{19}$ particularly true of those institutionalized elderly. Studies in both Turkey and Jordan showed that overall $59.9 \%$ of participants had a serum 25(OH)D level <30nmol// (deficiency). Serum 25(OH) $D$ was highest in women wearing western clothing and levels decreased to be lowest in traditional women wearing hijab and completely veiled women wearing niqab ${ }^{20}$. In our study, we found patients who had abnormal vitamin $\mathrm{D}$ level (deficient and insufficient) were more common in diseased group than healthy group $(84 ; 84.0 \%$ vs $50 ; 50.0 \%)$ which was statistically significant ( $p$-value $<0.01)$ that reflected low serum vitamin $D$ was associated with Rheumatological diseases. We also observed that low level of serum vitamin $D$ was more common in subjects with inadequate exposure to sunlight in comparison to adequately exposed population in study patients $(90.0 \%$ vs $80.0 \%$ ) that reflects inadequacy of sun exposure negatively affects serum vitamin $\mathrm{D}$ level.

A number of recent studies have highlighted the association between SLE and vitamin D deficiency. In a study in 92 SLE patients (90\% women, $98 \%$ white) it was found that $69(75 \%)$ and $14(15 \%)$ patients presented with vitamin D insufficiency and deficiency respectively ${ }^{21}$. Vitamin $D$ deficiency is also more common in RA patients and may be one of the causes leading to development or worsening of the disease. In one study it was found that $84 \%$ patients of RA were vitamin $D$ deficient versus only $34 \%$ of controls. ${ }^{14}$ The serum vitamin $D$ levels were also significantly lower in the RA patients (mean value of $21.05 \pm 10.02 \mathrm{ng} / \mathrm{ml}$ ) as compared to the controls (mean value $32.87 \pm 14.16 \mathrm{ng} / \mathrm{ml}$ ). There was a significant inverse correlation between serum vitamin $D$ levels and RA disease activity. We also found similar results, vitamin $D$ deficiency or insufficiency were in $100 \%$ cases of SLE patients and
$80 \%$ patients of RA cases. Other Rheumatological diseased patients such as AS, osteoporosis, osteoarthritis, etc also had similar level of vitamin $D$.

\section{Conclusion}

Vitamin D levels were lower in patients with Rheumatologic diseases than normal control group and female were more affected than male individuals. Life style also affected vitamin D status in patients with Rheumatologic diseases. Further large scale study is required pertinent to specific Rheumatologic disease to correlate effects of disease on vitamin D level and vice-versa.

\section{References}

1. Holick MF. Vitamin D deficiency. N Engl J Med 2007;357 (3):266-81.

2. Zitterman A. Vitamin D in preventive medicine: Are we ignoring the evidence? BJN 2003;89:552

3. Holick MF, Matsuoka LY, Wortsman J. Age, vitamin D, and solar ultraviolet. Lancet 1989; 2(8671):1104-5.

4. F Richard Bringhurst; Marie B. Demay; Henry M. Kronenberg; Bone and Mineral Metabolism in Health and Disease; Harrison's Principles of Internal Medicine, 20th ed; 402:7131-51.

5. Malabanan A, Veronikis IE, Holick MF. Redefining vitamin D insufficiency. Lancet 1998; 351:805-6.

6. Holick MF, Matsuoka LY, Wortsman J. Age, vitamin D, and solar ultraviolet. Lancet 1989; 2(8671):1104-5.

7. Zhou C, Assem M, Tay JC. Steroid and xenobiotic receptor and vitamin D receptor crosstalk mediates CYP24 expression and druginduced osteomalacia. J Clin Invest 2006; 116:1703-12.

8. Gatenby P, Lucas R, Swaminthan A. Vitamin D deficiency and risk factor for rheumatic diseases: an update: Curr Opin Rheumatol 2013; 25(2):184-91.

9. Michael F Holick and Tai C Chen; Vitamin D deficiency: a worldwide problem with health consequences; Am J Clin Nutr April 2008; 87(4):1080S-1086S.

10. Islam MZ, Akhtaruzzaman M, Lamberg-Allardt C. Hypovitaminosis $D$ is common in both veiled and non veiled Bangladeshi women. Asia Pac J Clin Nutr 2006; 15:81-7.

11. Islam MZ, Lamberg-Allardt, C, Karkkainen $M$ et al. Vitamin $D$ deficiency. A concern I premenopausal Bangladeshi omen of two socio-economic groups in rural and urban region. Eur $\mathrm{J}$ Clin Nutr 2002; 56:51-6. 
12. Grober U, Spitz J, Reichrath J et al. Vitamin D:Update 2013: From rickets prophylaxis to general preventive healthcare. Dermatoendocrinol 2013; 5(3):331-47.

13. Olezner $P$, Mullar A, Deschner $F$ et al. Rlationship between disease activity and serum levels of Vitamin D metabolites and PTH in Rheumatiod arthritis. Calcif Tissue Int 1998; 62:193-8.

14. Nareeda M, Sumit Pal SC, Sarabjot K. Assesment of Vitamin D in RheumatologyJ Nat Sci Biol Med 2018; 9(1)54-8.

15. Agmon-Levin N, Mosca M, Petri M, Shoenfeld Y. Systemic lupus erythematosus one diseaseor many? Autoimmune Rev 2012; 11:593-95.

16. Tohid $H$, Leila K, Yaser KB. Role of vitamin $D$ deficiency in systemic lupus erythematosus incidence and aggravation. Auto Immu Higlights 2018; 9(10)1.

17. Mok CC, Vitamin D and systemic lupus erythematosus: An update. Expert Rev. Clin Immunol 2013; 9:453-63
18. Rhew EY, Lee C, Eksarko $P$ et al. Homocystein, bone mineral density, and fracture risk over 2 years of follow up in women with or without systemic lupus erythematosus. Rheumatol 2008; 35:230-6.

19. Theiler R, Stahelin HB, Tyndall A, Binder K, Somorjai G, Bischoff HA. Calcidiol, calcitriol and parathyroid hormone serum concentrations in institutionalized and ambulatory elderly in Switzerland. Int J Vitam Nutr Res 1999; 69:96-105.

20. Mishal AA. Effects of different dress styles on vitamin D levels in healthyyoung Jordanian women. Osteoporos Int 2001; 12:931-35.

21. Ruiz-Irastorza G, Egurbide MV, Olivares $N$ et al. Vitamin D deficiency in systemic lupus erythematosus: prevalence, predictors and clinical consequences. Rheumatology 2008; 47:920-3. 